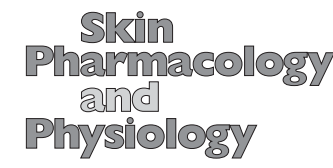

\title{
Editorial
}

Karger is very happy to announce a new initiative. It is based on the Editors' idea of collaboration between Dermatology and Skin Pharmacology and Physiology by synergizing the two journals. The idea was discussed and shaped during a recent meeting of both Editors and Karger in Berlin. Essentially, the idea can be summarized under the heading "knowledge transfer" and for the time being focuses on these two journals but could potentially expand and include all Karger journals in the field of dermatology. So what is the concrete understanding of "knowledge transfer" and what are the objectives?

\section{Context Translation}

One of the objectives is to connect the communities of the journals by "translating" the journal content on a specific topic into the other journal's reader's context - it will be relevant to readers of Dermatology to learn more about the pharmacological and physiological side of the skin as that may influence research and life in clinical practice and vice versa. Can the reader not just search for the respective literature and refer to the relevant paper in Dermatology or Skin Pharmacology and Physiology?

\section{Knowledge Transfer}

Certainly! However, the other objective of "knowledge transfer" is to bring several papers on the same topic together and give them a framework in an Editorial.
This said, it becomes clear why the term "knowledge transfer" was chosen - the ultimate objective is not to just cite journal articles since we all know that this qualifies as citation stacking [1] and both journals would run the risk of being suppressed from the Journal Citation Report [2]. This initiative is about connecting, discussing, and "translating" research for a readership that is related to the topic and has considerable overlap with it. Thus, a number of references will be found in the Editorials that do not include volumes relevant to Impact Factor, but will be cited for the purely scientific sake of "knowledge transfer."

The intention is to be stimulating and thought-provoking for the reader, and we hope to achieve our declared objectives - readers' feedback is certainly welcome! Gregor B.E. Jemec, Roskilde, Editor-in-Chief Dermatology Jürgen Lademann, Berlin, Editor-in-Chief Skin Pharmacology and Physiology Sandra Braun, Basel, Karger Publishers

\section{References}

1 http://wokinfo.com/media/pdf/jcr-suppression.pdf.

$2 \mathrm{https} / / /$ jcr.incites.thomsonreuters.com/JCRJournalHomeAction.action.

\section{KARGER}

(C) 2017 S. Karger AG, Basel 